\title{
Induction and repression of mammalian achaete-scute homologue (MASH) gene expression during neuronal differentiation of P19 embryonal
} carcinoma cells

\author{
JANE E. JOHNSON ${ }^{1}$, KATHRYN ZIMMERMAN ${ }^{1}$, TETSUICHIRO SAITO ${ }^{2}$ and DAVID J. \\ ANDERSON $^{2, *}$ \\ ${ }^{1}$ Division of Biology 216-76 and ${ }^{2}$ Howard Hughes Medical Institute, California Institute of Technology, Pasadena, CA 91125, USA \\ *To whom correspondence should be addressed
}

\begin{abstract}
Summary
MASH1 and MASH2, mammalian homologues of the Drosophila neural determination genes achaete-scute, are members of the basic helix-loop-helix (bHLH) family of transcription factors. We show here that murine P19 embryonal carcinoma cells can be used as a model system to study the regulation and function of these genes. MASH1 and MASH2 display complementary patterns of expression during the retinoic-acid-induced neuronal differentiation of P19 cells. MASH1 mRNA is undetectable in undifferentiated P19 cells but is induced to high levels by retinoic acid coincident with neuronal differentiation. In contrast, MASH2 mRNA is expressed in undifferentiated P19 cells and is repressed by retinoic acid treatment. These complementary expression patterns suggest distinct functions for MASH1 and MASH2 in development, despite their sequence homology. In retinoic-acid-treated P19 cells, MASH1 protein expression precedes and then overlaps expression of neuronal markers. However, MASH1 is expressed by a smaller proportion of cells than expresses such markers.
\end{abstract}

MASH1 immunoreactivity is not detected in differentiated cells displaying a neuronal morphology, suggesting that its expression is transient. These features of MASH1 expression are similar to those observed in vivo, and suggest that $P 19$ cells represent a good model system in which to study the regulation of this gene. Forced expression of MASH1 was achieved in undifferentiated P19 cells by transfection of a cDNA expression construct. The transfected cells expressing exogenous MASH1 protein contained E-box-binding activity that could be supershifted by an anti-MASH1 antibody, but exhibited no detectable phenotypic changes. Thus, unlike myogenic bHLH genes, such as MyoD, which are sufficient to induce muscle differentiation, expression of MASH1 appears insufficient to promote neurogenesis.

Key words: induction, repression, achaete-scute, MASH, neuronal differentiation, P19, embryonal carcinoma cells, basic helix-loop-helix.

\section{Introduction}

Helix-loop-helix proteins constitute a recently identified family of transcription factors which appear to be involved in the control of proliferation and cell type determination. This family includes the myc genes (Lüscher and Eisenman, 1990), the ubiquitously expressed E12/E47 gene (also known as E2A) (Murre et al., 1989a), myogenic determination genes such as MyoD (Weintraub et al., 1991), and the Drosophila neurogenic determination genes of the achaete-scute complex (Villares and Cabrera, 1987). These proteins share a basic region involved in DNA-binding, and an adjacent helix-loop-helix domain required for homoand heterodimerization (Davis et al., 1990). Together these domains constitute the basic helix-loop-helix
(bHLH) motif conserved among members of this family (Murre et al., 1989b). Certain bHLH proteins display a striking parallel conservation of amino acid sequence and cell type specificity of expression. For example, the Drosophila and $C$. elegans homologues of MyoD are $>85 \%$ identical to their mammalian counterparts (in the bHLH region), and are specifically expressed in myogenic precursor cells in their respective organisms (Krause et al., 1990; Michelson et al., 1990).

MASH1 and MASH2 appear to be mammalian homologues of the Drosophila achaete-scute genes, showing $>80 \%$ homology across the bHLH region but diverging considerably from all other bHLH genes (Johnson et al., 1990). The achaete-scute genes are required for the development of subsets of neurons in both the peripheral and the central nervous system of 
Drosophila (for review, see Ghysen and DamblyChaudiere, 1988). In addition, the achaete-scute genes are transiently expressed in neuronal precursors prior to the expression of the mature neuronal phenotype (Cabrera et al., 1987; Cubas et al., 1991; Romani et al., 1989). An extensive analysis of MASH1 protein expression during rat embryonic development has indicated that this gene is specifically expressed by subsets of cells in both the peripheral and the central nervous system (Lo et al., 1991). Moreover, MASH1 expression is transient; the protein appears before overt neuronal differentiation and disappears as neuronalspecific differentiation markers, such as SCG10 and neurofilament, are expressed. The neuronal specific and transient nature of MASH1 expression during rat embryonic development is similar, in its basic features, to that of achaete-scute in Drosophila (Cabrera et al., 1987; Cubas et al., 1991; Romani et al., 1989). Thus, as in the case of MyoD, the neurogenic bHLH genes appear to exhibit a parallel conservation of sequence and cell type specificity.

Given the complex and dynamic pattern of expression of MASH1 in vivo, studies of the regulation and function of this gene would be facilitated by a model cell culture system in which it was appropriately regulated. Previously, we showed that MASH1 and MASH2 are specifically expressed in PC12 cells and MAH cells, two neuronal precursor cell lines derived from the peripheral sympathetic nervous system (Johnson et al., 1990). However, expression in these lines is constitutive and only modestly regulated during neuronal differentiation. Here we have studied the expression of MASH1 and MASH2 in P19 murine embryonal carcinoma cells. P19 cells develop into neurons and glia when aggregated and treated with retinoic acid (Jones-Villeneuve et al., 1982; JonesVilleneuve et al., 1983; McBurney et al., 1988). We have found that the expression of MASH1, but not MASH2, is positively correlated with neural induction in these cells. MASH1 protein is transiently expressed in the nuclei of a subset of cells that express neuronal differentiation markers. The overall features of MASH1 expression in P19 cells are similar to those observed in vivo (Lo et al., 1991). Forced expression of MASH1 from a transfected cDNA is insufficient to bypass the requirement for retinoic acid. Thus, although MASH1 may be necessary for neuronal differentiation, it is not sufficient.

\section{Materials and methods}

\section{$P 19$ cell culture and retinoic acid treatment}

The P19 embryonal carcinoma cells were grown in DMEM supplemented with $7.5 \%$ calf serum and $2.5 \%$ fetal bovine serum and maintained as described elsewhere (Rudnicki et al., 1988). To aggregate the cells, $5-10 \times 10^{5}$ cells were cultured in $10 \mathrm{~cm}$ Petri-grade dishes (Falcon). Retinoic acid (Sigma) was added to a concentration of $1 \mu \mathrm{M}$ for 48 hours. The aggregates were refed every 48 hours with medium lacking the retinoic acid. For the experiment shown in Figs 5 and 6, the aggregates were plated onto tissue culture-grade chamber slides (Lab Tek, Inc.) 4 days after the initial aggregation and retinoic acid treatment.

\section{$R N A$ isolation and RNase protections}

Cytoplasmic RNA was isolated by phenol-chloroform extraction of postnuclear supernatants as described (Anderson et al., 1974). MASH1 and MASH2 mRNAs were analyzed by solution hybridization and RNase protection essentially as described (Melton et al., 1984). The antisense MASH1 probe was generated by $T 7$ RNA polymerase transcription of a PvulI digested MASH1 cDNA. The antisense MASH2 probe was generated by Sp6 RNA polymerase transcription of a plasmid containing a 250 bp XhoI-HindIII fragment of the MASH2 cDNA. The antisense $\gamma$-actin probe was generated by Sp6 polymerase transcription of a Fnu4H digested $\gamma$-actin plasmid (Enoch et al., 1986; Gunning et al., 1983). RNA samples $(5 \mu \mathrm{g})$ were hybridized with an excess of the ${ }^{32} \mathrm{P}$ labeled RNA probes in $80 \%$ formamide, $40 \mathrm{mM}$ PIPES $\mathrm{pH}$ $6.5,10 \mathrm{mM}$ EDTA, $400 \mathrm{mM} \mathrm{NaCl}$ for $>12$ hours at $50^{\circ} \mathrm{C}$. Hybrids were treated with $300 \mathrm{u} / \mathrm{ml}$ RNaseT1 (BRL) and 10 $\mathrm{ng} / \mathrm{ml}$ RNase A (Boehringer Mannheim) for 20 minutes at $42^{\circ} \mathrm{C}$, followed by a 30 minutes incubation at $37^{\circ} \mathrm{C}$ with 1 $\mu \mathrm{g} / \mathrm{ml}$ proteinase $\mathrm{K}, 0.5 \%$ SDS. Protected bands were analyzed by electrophoresis on a $6 \%$ polyacrylamide $/ 7 \mathrm{M}$ urea gel. Densitometry was performed using a Pharmacia LKB Ultrascan XL laser densitometer.

\section{Immunofluorescence staining}

Monoclonal 5A5 producing hybridoma cells (Dodd et al., 1988 ), and the monoclonal SSEA-1 hybridoma supernatant (Solter and Knowles, 1978) were obtained from the Developmental Studies Hybridoma Bank [NICHD (NO1-HD-62915)]. 5A5 hybridoma supernatant was used undiluted. SSEA-1 supernatant was used at a 1:3 dilution. Monoclonal antibody HNK-1 (hybridoma cells obtained from ATCC) was used as an ascites fluid diluted 1:250. In general, 5A5, HNK-1 and SSEA-1 labeling of surface antigens was performed on live cells for 30 minutes followed by incubation with FITCgoat anti-mouse IgM (TAGO) and postfixation in $3.7 \%$ formaldehyde for 10 minutes at room temperature. For flow cytometry, the retinoic acid treated aggregates were stained in suspension then dispersed by trituration in PBS containing 1 mM EDTA before postfixing in $1 \%$ formaldehyde for 10 minutes at room temperature and storing at $4^{\circ} \mathrm{C}$ until analyzed on a cell sorter (Ortho). For double staining experiments, the postfixed cells were permeabilized with $0.1 \% \mathrm{NP}-40$ and incubated with anti-MASH1A hybridoma supernatant (1:1 dilution) overnight at $4^{\circ} \mathrm{C}$ (Lo et al., 1991). Secondary antibody was either rhodamine- or phycoerythrin-goat antimouse IgG (Southern Biotechnology Associates, Inc.). For staining with anti-MASH1A alone, cells were fixed in $3.7 \%$ formaldehyde 10 minutes at room temperature, permeabilized with $0.1 \%$ NP- 40 , and incubated with the hybridoma supernatent overnight at $4^{\circ} \mathrm{C}$. Staining was visualized using an avidin-biotin-HRP system (Vectastain $A B C$ kit, Vector Labs, Burlingame, $\mathrm{CA}$ ) according to the manufacturer's instructions.

For separation of 5A5-positive and negative P19 populations for RNA analysis, activated magnetic beads (Dynal) were coated with a goat anti-mouse IgM as described by the manufacturer. These beads were then conjugated to the 5A5 antibody, reacted with dispersed retinoic-acid-treated P19 aggregates, and the 5A5-positive cells separated from the 5A5-negative cells using a magnet. Cytoplasmic RNA was prepared from the two fractions. 
Preparation of nuclear extract and gel shift assays

P19 cells were aggregated for 4 days in the presence of $1 \mu \mathrm{M}$ retinoic acid then plated onto tissue-culture-grade substratum for 1 day before harvest. Nuclear extracts were prepared as described by Schreiber et al. (Schreiber et al., 1989). Gel shift assays were performed as described (Benezra et al., 1990), except that the high ionic strength buffer used for electrophoresis was as described by Murre et al. (Murre et al., 1991). The oligonucleotides used contain the IgH-enhancer-like sequence in the wild-type muscle creatine kinase enhancer (top strand: GATCCCCCCAACACCTGCTGCCTGA) or this sequence mutated within the E-box concensus (top strand: GATCCCCCCAACACGGTAACCCTGA) (Jaynes et al., 1988; Lassar et al., 1989). Nuclear extract $(7.5 \mu \mathrm{g})$ was incubated with $0.5 \mathrm{ml}$ ascites at $37^{\circ} \mathrm{C}$ for 20 minutes, then mixed with $0.75 \mathrm{ng}$ of double-stranded oligonucleotide probe $(20,000 \mathrm{cpm} / \mathrm{ng})$. For competition experiments, $50 \mathrm{ng}$ of unlabeled wild-type or mutant oligonucleotide was also added.

\section{Plasmids and transfection}

To construct the MASH1 expression vector pRSVM1E, a Sac1-Sal1 fragment from the MASH1 cDNA Nj1-13 was cloned into pRSVSV40, an expression construct containing the Rous sarcoma virus LTR, a polylinker, and SV40 sequences containing the small $t$ intron and poly $(A)$ addition signal (J. Montgomery, unpublished). The Sac1 site in the MASH1 cDNA is located between the first 2 methionines which are 6 amino acids apart. Thus, the protein expressed from this vector lacks the first 6 amino acids. This truncated protein has equivalent DNA binding and transcriptional activation activity in comparison to the full length protein (Johnson et al., in preparation). pRSVM1E was co-transfected with pUCneo (SV40 early promoter driving the neomycin resistance gene) into P19 cells using the calciumphosphate DNA precipitation protocol (Wigler et al., 1979). Cultures of $10^{6}$ cells were exposed to $20 \mu \mathrm{g}$ plasmid DNA for $16-20$ hours then split into three $10 \mathrm{~cm}$ dishes. Stable transformants were selected in $500 \mu \mathrm{g} / \mathrm{ml} \mathrm{G} 418$ the following day. Colonies were pooled after 8-10 days of selection, cultures expanded and then analyzed for expression of MASH1, 5A5, HNK-1 and SSEA-1 by immunocytochemistry.

\section{Results}

\section{Complementary regulation of $\mathrm{MASH1}$ and $\mathrm{MASH} 2$}

by retinoic acid

P19 cells undergo neuronal differentiation following aggregation and treatment with retinoic acid (JonesVilleneuve et al., 1982; Jones-Villeneuve et al., 1983). To determine whether the regulation of MASH1 and/or MASH2 mRNAs was correlated with neuronal differentiation, we analyzed the timecourse of their expression following a two-day exposure of aggregated cells to $1 \mu \mathrm{M}$ retinoic acid. Under these conditions, MASH1 and MASH2 mRNAs display complementary patterns of expression (Fig. 1). MASH1 mRNA is not detectable in undifferentiated P19 cells, but is detected at low levels by 12 hours; expression then increases through day 6 despite the withdrawal of retinoic acid on day 2 (Fig. 1A and Fig. 2A). The levels of MASH1 expression attained were similar to those observed in MAH cells, a peripheral sympathetic precursor cell line
(Birren and Anderson, 1990) in which MASH1 is expressed (Johnson et al., 1990) (Fig. 1A, MAH). In contrast, MASH2 mRNA is expressed in undifferentiated P19 cells but declines to undetectable levels by day 2 (Fig. 1B and Fig. 2A). Densitometric analysis indicates that the maximal abundance of MASH1 mRNA is 50-fold greater than MASH2 mRNA in undifferentiated cells (Fig. 2A). Aggregation of P19 cells without addition of retinoic acid, which induces differentiation of a small percentage of cells to an embryonic endodermal phenotype (Jones-Villeneuve et al., 1982), had no effect on the levels of MASH1 or MASH2 mRNAs (Fig. 1, Agg Only). These data therefore suggest that reciprocal changes in the expression of MASH1 and MASH2 mRNAs occur specifically upon retinoic-acid-induced differentiation of P19 cells.

\section{The extent of MASH1 mRNA induction correlates with the proportion of cells expressing neuronal markers}

To define further the relationship of MASH1 and MASH2 expression to neuronal differentiation in the P19 cultures, the appearance of two neuronal markers was monitored following retinoic acid treatment using the monoclonal antibodies HNK-1 (Abo and Balch, 1981) and 5A5 (Dodd et al., 1988). 5A5 recognizes the highly polysialylated form of NCAM, an early and specific pan-neuronal marker in vivo (Dodd et al., 1988). HNK-1 recognizes a carbohydrate epitope but has been shown to be neuron-specific in retinoic-acidtreated P19 cultures (McBurney et al., 1988). Fluorescence microscopy of differentiating P19 cultures (see below) indicates that these markers are expressed not only by neurons, but also by morphologically undifferentiated cells which may be neuronal precursors.

The percentage of HNK-1 and 5A5-positive cells in the population was analyzed by flow cytometry in parallel with analysis of the MASH1 and MASH2 mRNAs following retinoic acid treatment. Significant numbers of 5A5-positive and HNK-1-positive cells are observed on day 4 but not on day 2, during which interval MASH1 mRNA accumulates to high levels and MASH2 mRNA is no longer detectable (Fig. 2, compare $\mathrm{A}$ and $\mathrm{B}$ ). The percentage of cells expressing the two neuronal markers, like the levels of MASH1 mRNA, reaches maximal levels by day 6 . At this time HNK-1 and 5A5-positive cells constitute $65 \%$ of the total population (Fig. 2B; Fig. 3). As the percentage of HNK-1 and 5A5-positive cells declines following day 6, (perhaps reflecting an overgrowth of non-neuronal cells in the culture), MASH1 mRNA levels fall and MASH2 mRNA increases. Lower doses of retinoic acid, which yield lower percentages of 5A5-positive cells in the P19 cultures (Edwards et al., 1983), also yielded lower amounts of MASH1 mRNA (data not shown). In cultures aggregated in the absence of retinoic acid, which resulted in no change in MASH1 and MASH2 mRNA expression (Fig. 1 AGG only), no 5A5 immunoreactivity was detected (Fig. 3B). These data thus indicate a strong correlation between the percent- 
A. MASH-1

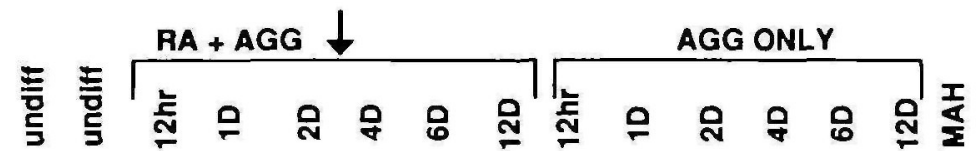

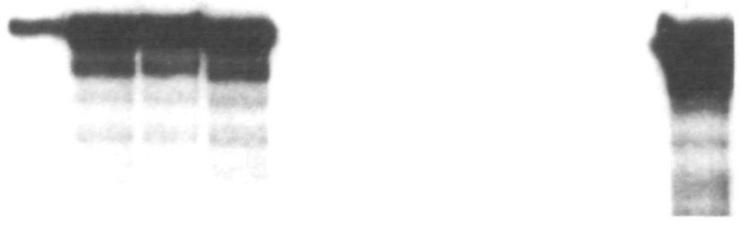

actin

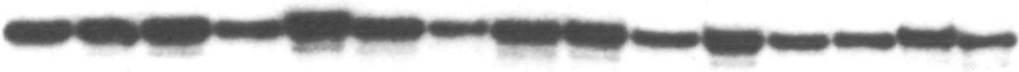

B. MASH-2
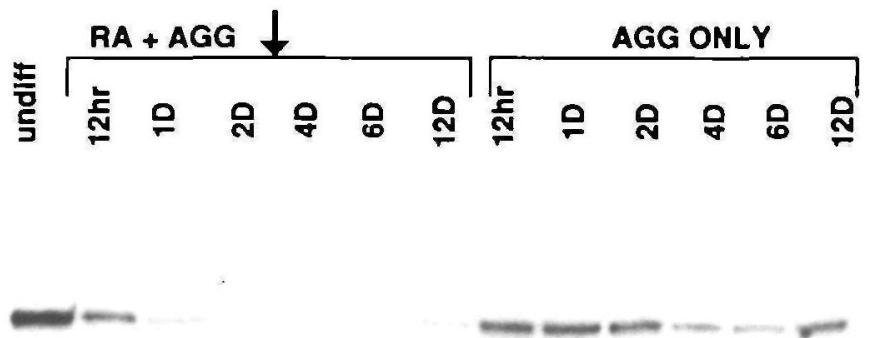

actin

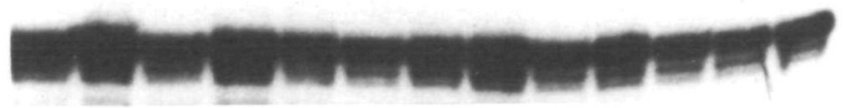

Fig. 1. RNase protection analysis of MASH1 and MASH2 mRNAs in a timecourse of retinoic-acidtreated P19 aggregates. Cytoplasmic RNA was analyzed from P19 aggregates cultured with (RA + AGG) or without ( $A G G$ only) retinoic acid from 12 hours to 12 days. Undiff: untreated P19 monolayers. MAH is a neuronal precursor cell line (Birren and Anderson, 1990) and serves as a positive control. The arrow indicates the time when retinoic acid was removed from the cultures. (A) MASH1protected mRNA transcripts. (B) MASH2-protected RNA transcripts. The actin band controls for the amount of RNA in each lane. Panel (B) is a longer exposure than panel (A). age of cells expressing neuronal markers and the extent of MASH1 mRNA induction. MASH2 mRNA, by contrast, is inversely correlated with the size of the neuronal population and with the expression of MASH1 mRNA.

\section{MASH1 immunoreactivity overlaps the expression of neuronal markers}

The foregoing data indicated a parallel rise in MASH1 mRNA levels and the expression of neuronal markers in differentiating P19 cells. However, these measurements failed to reveal the precise relationship between the expression of MASH1 and neuronal markers at the cellular level. To address this issue, we used doublelabel imunofluorescence to simultaneously detect MASH1 and 5A5 or HNK-1. MASH1 immunoreactivity was not detected in undifferentiated P19 cells. The earliest detectable expression of MASH1 immunoreactivity following retinoic acid treatment was observed at day 3 and was clearly localized to the nucleus
(Fig. 4C). Aggregates containing MASH1-positive nuclei at day 3 were not detectably labeled by 5 A5 (Fig. 4B). By day 4, however, such MASH1-positive aggregates were clearly labeled by 5 A5 (Fig. 4, E and F). These data show that the appearance of MASH1 immunoreactivity precedes that of the neuronal marker 5A5, and that 5A5 labeling appears in aggregates containing MASH1-positive cells. However, although regions of the aggregates containing MASH1-positive and 5A5-positive cells clearly overlap, it was not possible to determine at this level of resolution whether individual cells co-express both markers.

To determine whether any MASH1-positive cells coexpress 5A5, two different methods were used. In the first, 5A5-positive cells were isolated using antibodycoated magnetic beads (see Materials and Methods) and analyzed for MASH1 expression by RNase protection. MASH1 mRNA was clearly detected in the 5A5positive cell population (Fig. 5A). In the second method, the co-expression of MASH1 and 5A5 in single cells was detected by two-color immunofluorescence 
A

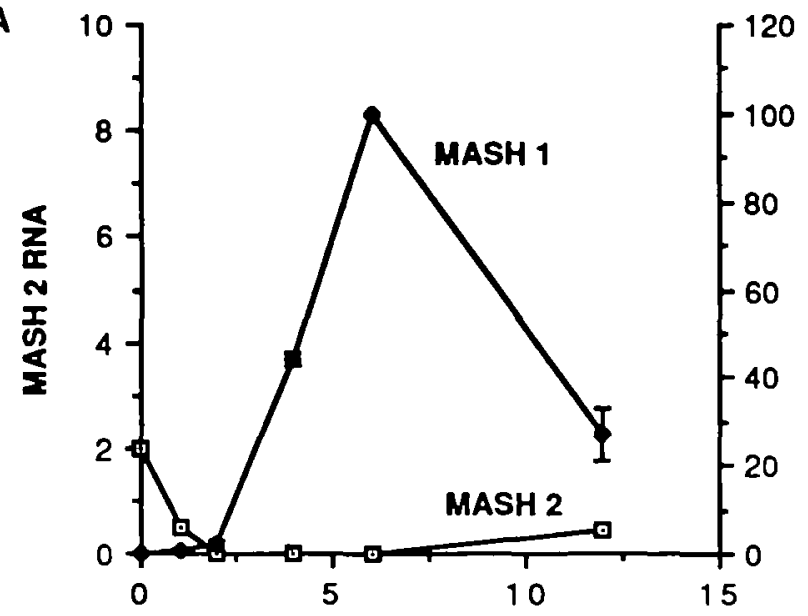

B

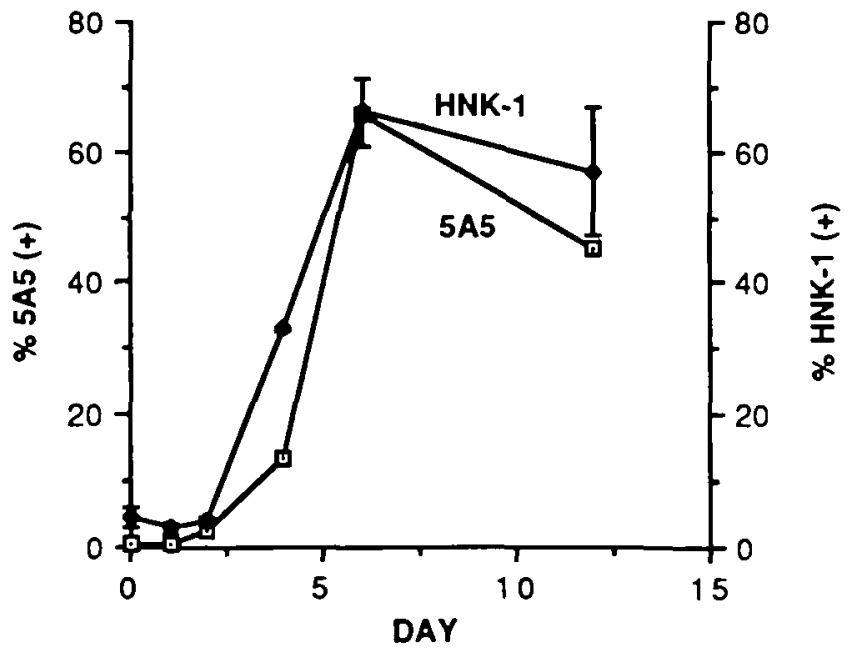

Fig. 2. Correlation of MASH mRNA expression with neuronal induction of P19 cells. (A) Densitometry was performed and averaged from two independent RNase protection experiments, one of them shown in Fig. 1. The intensity of each MASH1 or MASH2 protected band was normalized to the respective $\gamma$-actin band. The relative levels of MASH1 to MASH2 were estimated using $\gamma$-actin as an internal standard and assuming similar specific activities of the MASH1 and MASH2 probes. (B) The percentage of 5A5- and HNK-1-positive cells was determined by fluorescence activated cell sorting of retinoic-acid-treated P19 cultures prepared in parallel with the RNase protection experiments in (A). The data for HNK-1 represent the average of two experiments and the error bars represent the range.

(Fig. 5B). To quantify these data, aggregates were dissociated and double-labeled for MASH1 and 5A5 in a single-cell suspension. This experiment confirmed that up to $67 \%$ of MASH1-positive cells are co-labeled by $5 A 5$ at day 6 ( $n=611$ cells counted). Thus, both methods indicate that MASH1 and 5A5 can be expressed in the same cells. However, both methods also indicate that MASH1 is expressed by 5A5-negative cells as well (Fig. 5A and data not shown). All MASH1- positive nuclei appear to be present in 5A5-positive aggregates (Fig. 4), indicating that MASH1-positive, 5A5-negative cells are intermingled with MASH1positive, 5A5-positive cells. Given that MASH1 protein precedes $5 \mathrm{~A} 5$ on day 3 , a likely explanation for these observations is that the MASH1-positive, 5A5-negative cells are precursors of MASH1-positive, 5A5-positive cells, although this is presently difficult to prove.

In our retinoic-acid-treated P19 cultures, up to $65 \%$ of the cells express 5A5 at day 6 , as determined by flow cytometry (Fig. 3A). Efforts to determine the proportion of MASH1-positive cells by FACS were unsuccessful due to the nuclear localization of the antigen. As an alternative approach to this question, dissociated cell suspensions of retinoic-acid-treated aggregates were immunolabeled for MASH1 using a sensitive avidin-biotin peroxidase method (see Materials and Methods), and the proportion of positive cells determined by manual counting. This analysis indicated that MASH1-positive cells constitute approximately $3-5 \%$ of the P19 population at day 3, when immunoreactivity is first detected (two independent experiments; $n=5,611$ cells counted). The proportion of MASH1-positive cells remains roughly constant between days 3 and 6 (data not shown), while the expression of MASH1 mRNA increases continuously over this interval (Fig. 2). Although differences in the methods used to analyze 5A5 and MASH1 expression make difficult an accurate quantitative comparison of these two antigens, the data strongly suggest that MASH1 is expressed by a smaller proportion of cells than expresses 5A5.

The preceding analysis does not distinguish whether 5A5-positive cells expressing MASH1 are differentiated neurons or neuronal precursors. In order to examine the expression of MASH1 in cells displaying a fully differentiated neuronal morphology, aggregated and retinoic-acid-treated P19 cells were plated onto a tissue culture substratum at day 4 . Two days later, neurons at the edges of the aggregates had extended processes over a halo of flat cells which had migrated onto the substratum. These cultures were examined by double-label immunofluorescence for MASH1 and 5A5. MASH1 immunoreactivity was not detected in process-bearing 5A5 neurons (Fig. 6, D-F). However, MASH1 immunoreactivity co-localizes to aggregates containing 5A5-positive cells and not to the 5A5negative flat cells (Fig. 6, A-C). These data show that MASH1 immunoreactivity is associated with 5A5positive cell clusters which may contain immature neurons or neuronal precursors, but is not detected in fully differentiated neurons. This implies that the expression of MASH1 is transient in P19 cultures undergoing neuronal differentiation.

\section{Additional HLH proteins are induced by retinoic acid} in P19 cells

The low percentage of P19 cells expressing MASH1 after retinoic acid treatment could reflect a transient expression of this gene by all cells or by a subset of cells. In the latter case, MASH1 might be only one of several 
Retinoic Acid + Aggregation

(Day 6)
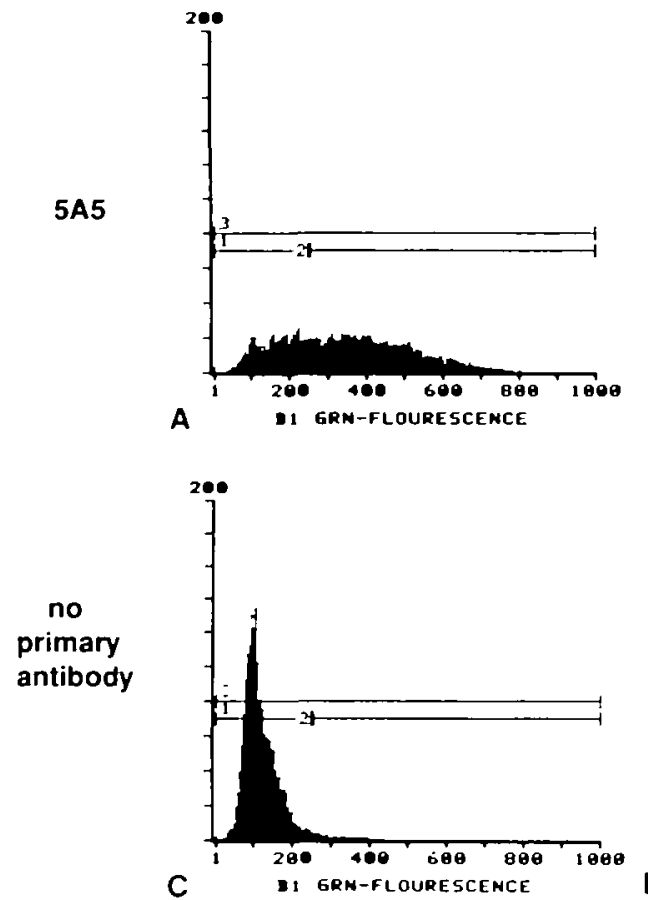

Aggregation Only

(Day 6)
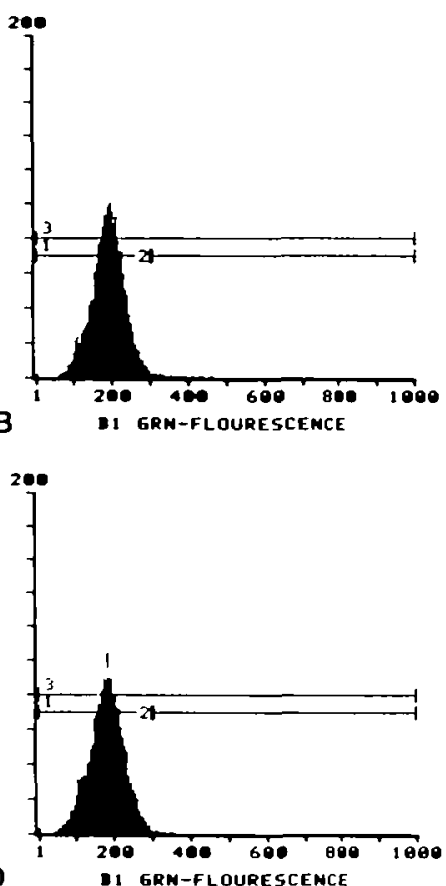

Fig. 3. Histogram illustrating distribution of 5A5 labeling in P19 cells aggregated for 6 days and exposed to retinoic acid on days 1 and 2 . Ordinate, cell number; abscissa, fluorescence intensity (log scale). (A) Differentiating cells labeled with monoclonal antibody $5 \mathrm{~A} 5$ and fluorescein-conjugated secondary antibody; (C) control in which the primary antibody was omitted. Note the difference in fluorescence distribution. Note also the absence of any labeling in cells aggregated without retinoic acid treatment (compare B, labeled with $5 \mathrm{~A} 5$ and $\mathrm{D}$, lacking primary antibody). The area bracketed by " 2 " was used to calculate the percentage of positive cells. different bHLH proteins expressed by differentiating P19 cells. To investigate this possibility, we assayed nuclear extracts from P19 cells by an electrophoretic mobility shift assay (EMSA) using an oligonucleotide containing an IgH enhancer-like element ("E-box") from the muscle creatine kinase gene (Jaynes et al., 1988; Lassar et al., 1989). The detection of factors able to bind specifically to this oligonucleotide would suggest the presence of one or more proteins in the bHLH class (Murre et al., 1989a).

Nuclear extracts prepared from undifferentiated P19 cells did not contain measureable levels of E-boxbinding activity (Fig. 7, lanes 1-7), suggesting either that MASH2 protein is not functional or is expressed below the detection limit of this assay. However, extracts prepared from retinoic-acid-treated cultures contained a protein or proteins that produced a strong signal in the EMSA assay (Fig. 7, lane 8, lower arrow). This binding activity was competed by an excess of unlabeled oligonucleotide (Fig. 7, lane 14), but not by an excess of an oligonucleotide containing mutations that disrupt the concensus E-box and abolish binding of MASH-E12 heterodimers (Fig. 7, lane 13) (Johnson et al., submitted). To determine what fraction of the Ebox-binding activity is contributed by MASH1, we performed a "super-shift" experiment by adding monoclonal anti-MASH1 antibodies to the EMSA reaction. Two of three independent anti-MASH1 monoclonal antibodies caused the appearance of a new band of higher molecular weight (Fig. 7, lanes 10 and 11, upper arrow). This band was not observed with a control antibody of the same subtype (Fig. 7, lane 9), indicating that it is specific for MASH1. Anti-MASH1C did not cause a super shifted band, and may recognize an epitope that is blocked by oligomerization and/or DNA binding (T. S., unpublished observations). The intensity of the super-shifted band could be increased by supplementing the extracts with in vitro translated MASH1 and E12 (not shown), demonstrating that antibody was present in excess. The small proportion of E-box-binding activity supershifted by the antibody therefore suggests that MASH1 constitutes only a fraction of the total bHLH proteins induced by retinoic acid in P19 cells. These other, putative bHLH proteins may constitute a single, highly abundant species or a diversity of lower abundance species.

Constitutive expression of MASH1 in undifferentiated P19 cells yields functional protein but is not sufficient to induce neuronal differentiation

Expression of MyoD, a muscle-specific relative of MASH1, is sufficient to cause myogenic differentiation in a number of cultured mammalian cell types (Davis et al., 1987; Weintraub et al., 1989). Since MASH1 expression is correlated with neuronal differentiation in P19 cells and precedes that of other neuronal differentiation markers, we wished to determine whether expression of MASH1 was similarly sufficient to promote neuronal determination. P19 cells were cotransfected with pRSVM1E, a MASH1 cDNA under the control of the Rous sarcoma virus LTR, and a plasmid containing the neomycin resistance gene. Preliminary experiments using transient transfection failed to reveal evidence for phenotypic changes induced by overexpression of MASH1. Stably transformed G418-resistant cells were therefore generated, and first examined for expression of MASH1 by 

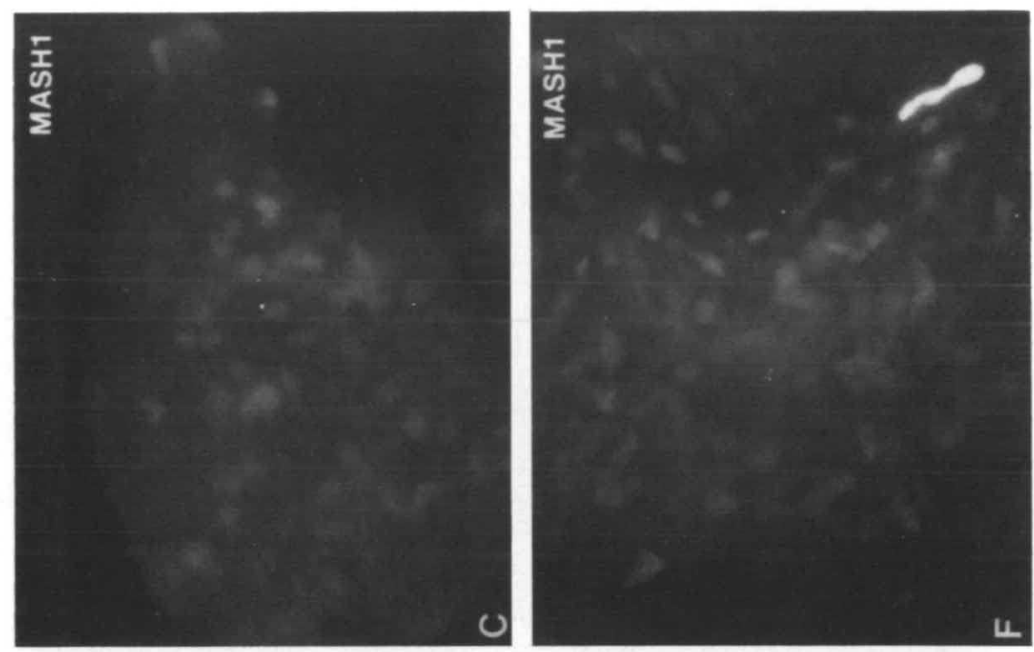

을

要

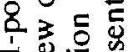

索焉

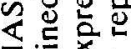

牙

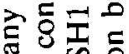

है

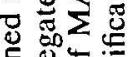

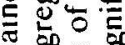

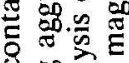

ลำ产豞

II

要

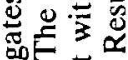

政地

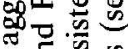

额言

品 3.5 $\infty .5$

6 过

祀害产

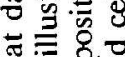

$\overrightarrow{8}$

츤

ถู

$m$

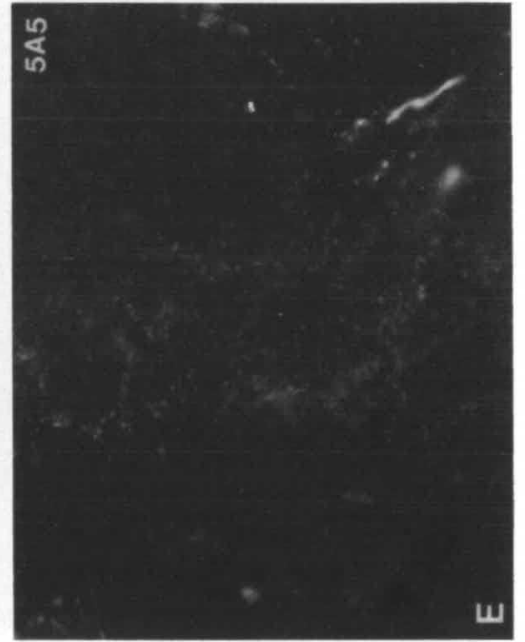

$\Xi \Sigma=8$

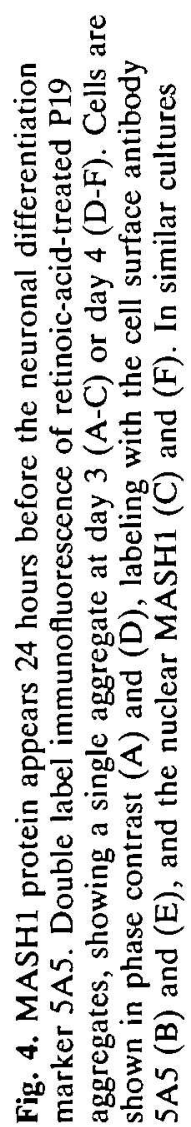




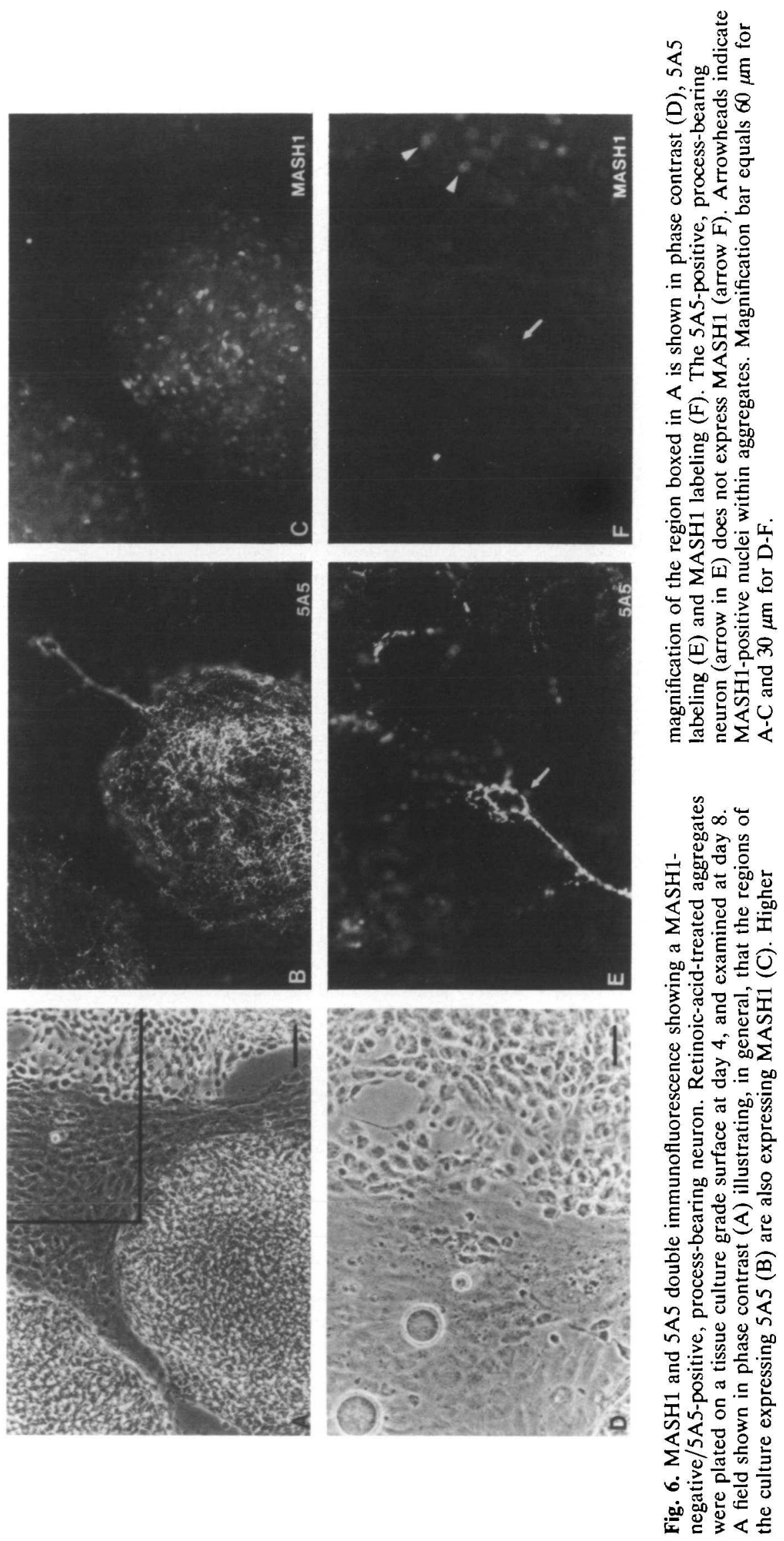


A

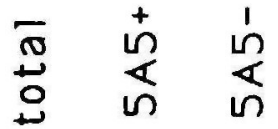

\section{MASH 1}

actin

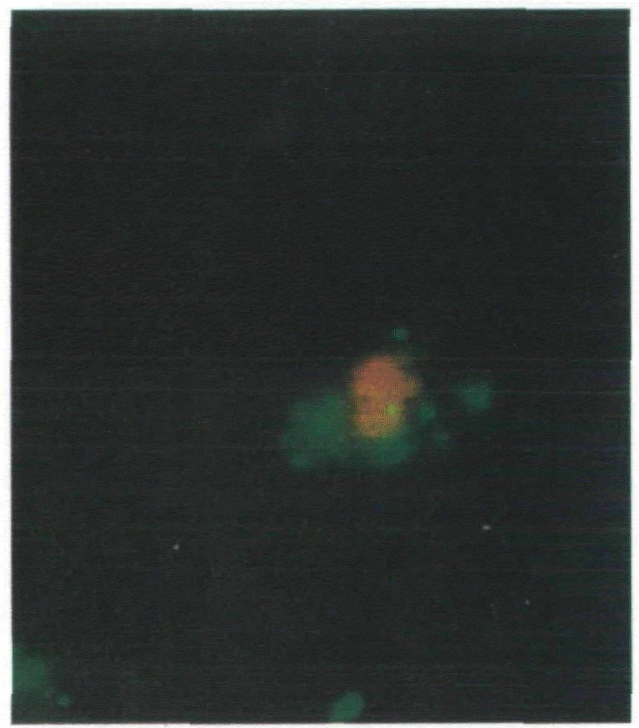

Fig. 5. MASH1-positive cells co-express 5A5. (A) MASH1 RNase protection analysis of day 4 retinoic-acid-treated P19 aggregates (total), the 5A5-positive fraction (5A5+), and 5A5-negative fraction (5A5-). Cells were separated as described in Materials and Methods. The $\mu$-actin serves as a control for the amount of RNA assayed. Approximately equal amounts of RNA were analyzed in each lane, but much less RNA was recovered from the $5 A 5+$ than the 5A5 - fraction, as expected from the low proportion of 5A5+ cells at this stage (see Fig. 2B). (B) Co-expression of MASH1 and the neuronal marker $5 \mathrm{~A} 5$ in the same cell. Plated retinoic-acid-treated P19 aggregates were assayed on day 6 for MASH1 and 5A5 by two-color immunofluorescence. False-color superimposed FITC and rhodamine images were obtained using VidIM software developed by S. Fraser, J. Stolber and G. Belford (unpublished). The picture was taken with an SIT camera on a Zeiss Universal epifluorescence microscope. The nuclear staining for MASH1 (red) is surrounded by cellsurface labeling for 5A5 (green) in a single, well-isolated cell. 

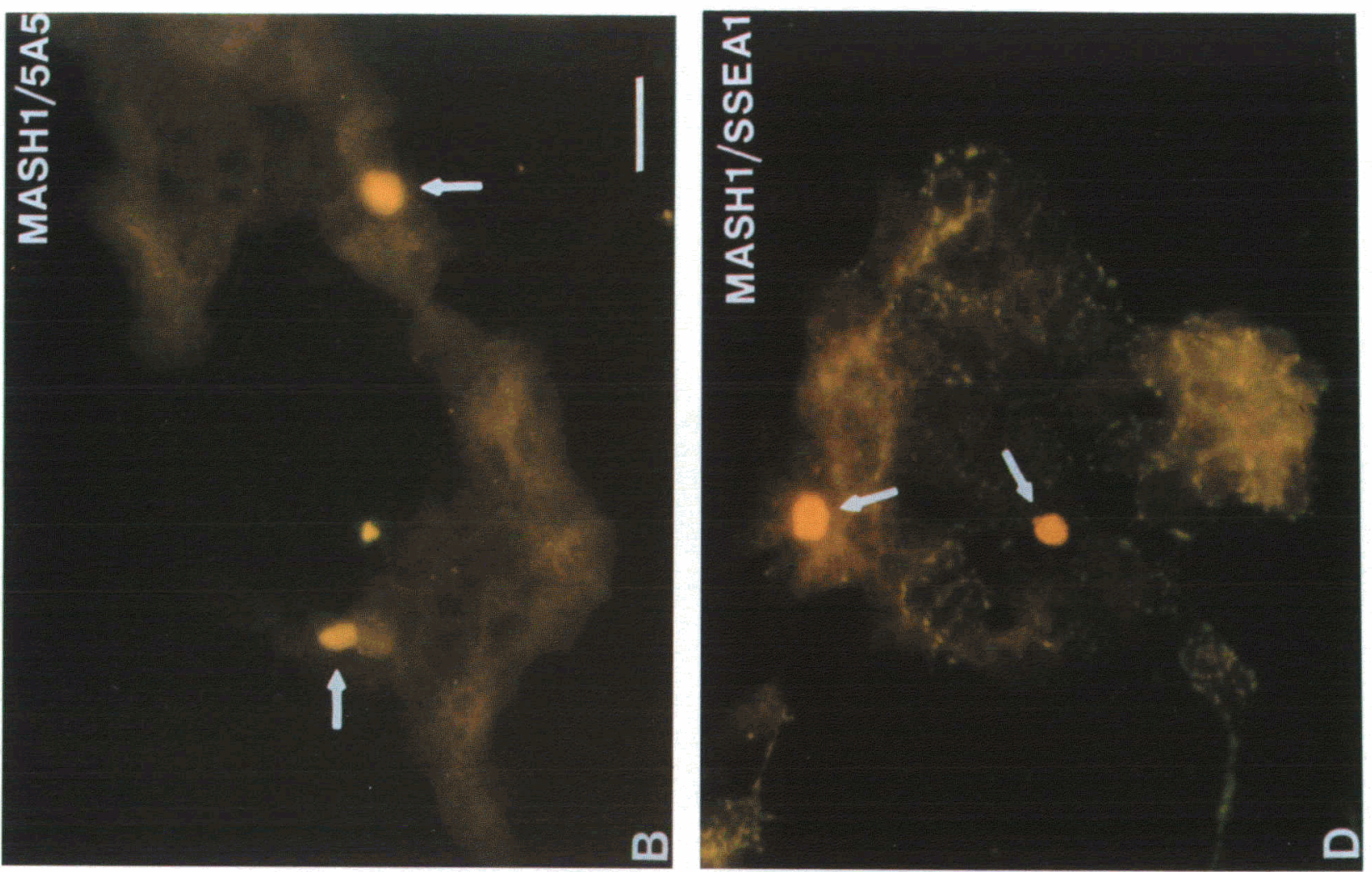

는.

동.=

毛元

交

등

\%

들 孚

站

$\widehat{D}^{5} \leftarrow$

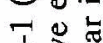

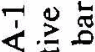

山 ㅇํㅇㅇำ

的导

o.

Oิ

늘

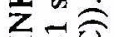

王它

色文 奇

น

的的实

$\pi$ त

言至此 产总要
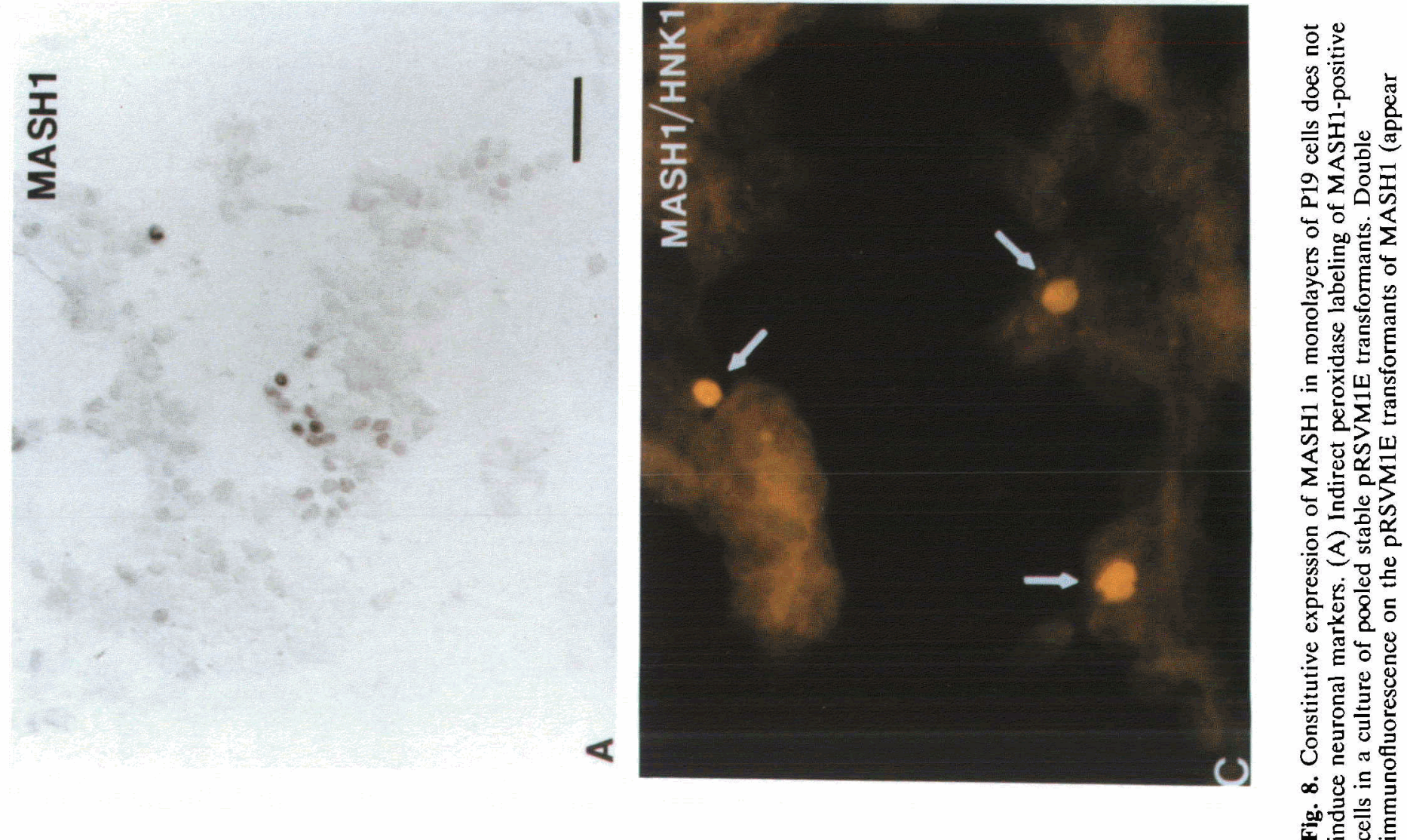

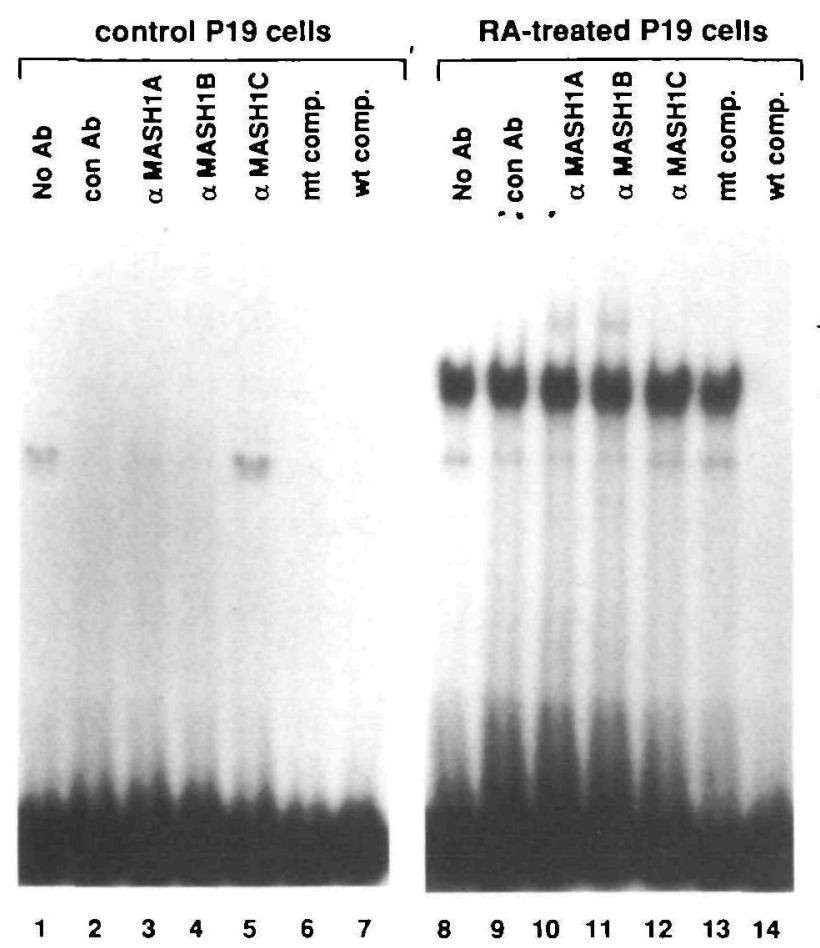

Fig. 7. Induction of E-box binding activity in retinoic-acidtreated P19 cells. Extracts of untreated (control) P19 cells (1-7) or retinoic-acid (RA)-treated P19 cells (8-14) were used in an electrophoretic mobility shift assay to test binding to an oligonucleotide containing the E-box (see Materials and Methods). Added to the extracts were no antibody $(1,8)$, control antibody of the same subtype as the test antibodies $(2,9)$, anti-MASH1A $(3,10)$, anti-MASH1B $(4,11)$, anti-MASH1C $(5,12)$, unlabeled mutant oligonucleotide $(6,13)$ or unlabeled wild-type oligonucleotide $(7,14)$. Arrow indicates the gel shifted band. The arrow* indicates the antibody dependent, "supershifted" band. The complex formed in the control extracts must be non-specific since both mutant and wildtype oligonucleotides compete for the binding $(6,7)$.

immunocytochemistry. We found that MASH1 was expressed in only a small percentage of these pooled transformants, even though they were maintained in selection medium (Fig. 8A). These limitations precluded an analysis of the effects of forced MASH1 expression in mass cultures. Therefore, the effect of constitutive expression of MASH1 was examined using a single-cell assay.

Stably transfected cells were doubly-labeled with the anti-MASH1A antibody, and either the neuronal markers 5 A5 or HNK-1, or a marker for the undifferentiated P19 cell, SSEA-1 (McBurney et al., 1988; Solter and Knowles, 1978). This analysis indicated that individual MASH1-positive P19 cells expressed neither 5 A5 nor HNK-1, nor changed their morphology, in the absence of retinoic acid (Fig. 8, B and C). Moreover, many MASH1-positive cells continued to express SSEA-1 (Fig. 8D). Thus, constitutive expression of MASH1 appears insufficient to promote neuronal differentiation in P19 cells.

To determine whether the MASH1 protein expressed from the transfected cDNA was functional in undifferentiated P19 cells, we examined the activity of transfected MASH1 in nuclear extracts from clones of stably transformed cells using a gel-shift DNA-binding assay as described earlier (Fig. 7). From two clones containing the highest proportion of MASH1-immunoreactive cells (up to $30 \%$ ), a shifted complex was obtained using an E-box-containing oligonucleotide (Fig. 9, lanes 13 and 14). The mobility of this complex was similar to that observed for in vitro-translated MASH1 and E12 (Fig. 9 , lane 16, lower arrow). Such shifts were not observed using wild-type undifferentiated P19 cells (Fig. 9, lane 1 and Fig. 7, lanes 1-7). The mobility of the shifted species was specifically retarded by incubation with anti-MASH1 monoclonal antibody (Fig. 9, lanes 9 and 12) but not by a control antibody (Fig. 9 , lanes 8 and 11) or by incubation without antibody (Fig. 9, lanes 7 and 10) (although such control incubations reduced the intensity of the lower band, perhaps due to proteolytic degradation). The antibody super-shifted species was similar in size to that obtained using in vitro-translated MASH1 plus E12 (Fig. 9, lane 16, upper arrow), or extracts of wild-type retinoic-acid-treated P19 cells (Fig. 9, lane 6); it was not detected in undifferentiated cells (Fig. 9, lane 3). Since MASH1 homo-oligomers are unable to bind the E-box probe used in this study except at very high concentrations (Johnson et al., submitted), these data suggest that the exogenous MASH1 expressed in stably transformed, undifferentiated P19 cells is able to complex with E12 or an E12like protein to form functional DNA-binding complexes. Moreover, the amounts of this activity are similar to those observed in wild-type P19 cells exposed to retinoic acid. Nevertheless, no differences in neural marker expression, nor in the rate or extent of the response to retinoic acid, were detected in these transformed cells (L. Lo, unpublished data).

\section{Discussion}

The amino acid sequence of MASH1 is more than $80 \%$ identical, in the bHLH domain, to that of the four achaete-scute complex genes of Drosophila (Campuzano et al., 1985; Gonzalez et al., 1989; Villares and Cabrera, 1987), and is more closely related to these neurogenic determination genes than to other, mammalian members of the bHLH family (Johnson et al., 1990). A detailed immunocytochemical analysis of MASH1 expression during rat embryogenesis has revealed that this protein is transiently expressed by spatially restricted subsets of neural precursor cells (Lo et al., 1991), consistent with the hypothesis that MASH1 is a vertebrate neuronal determination gene. These observations raise the related questions of how MASH1 functions during neurogenesis, and what factors regulate its complex and dynamic pattern of expression.

As a first step towards addressing these questions, we have identified a cell culture system in which MASH1 expression is induced concomitant with neuronal differ- 


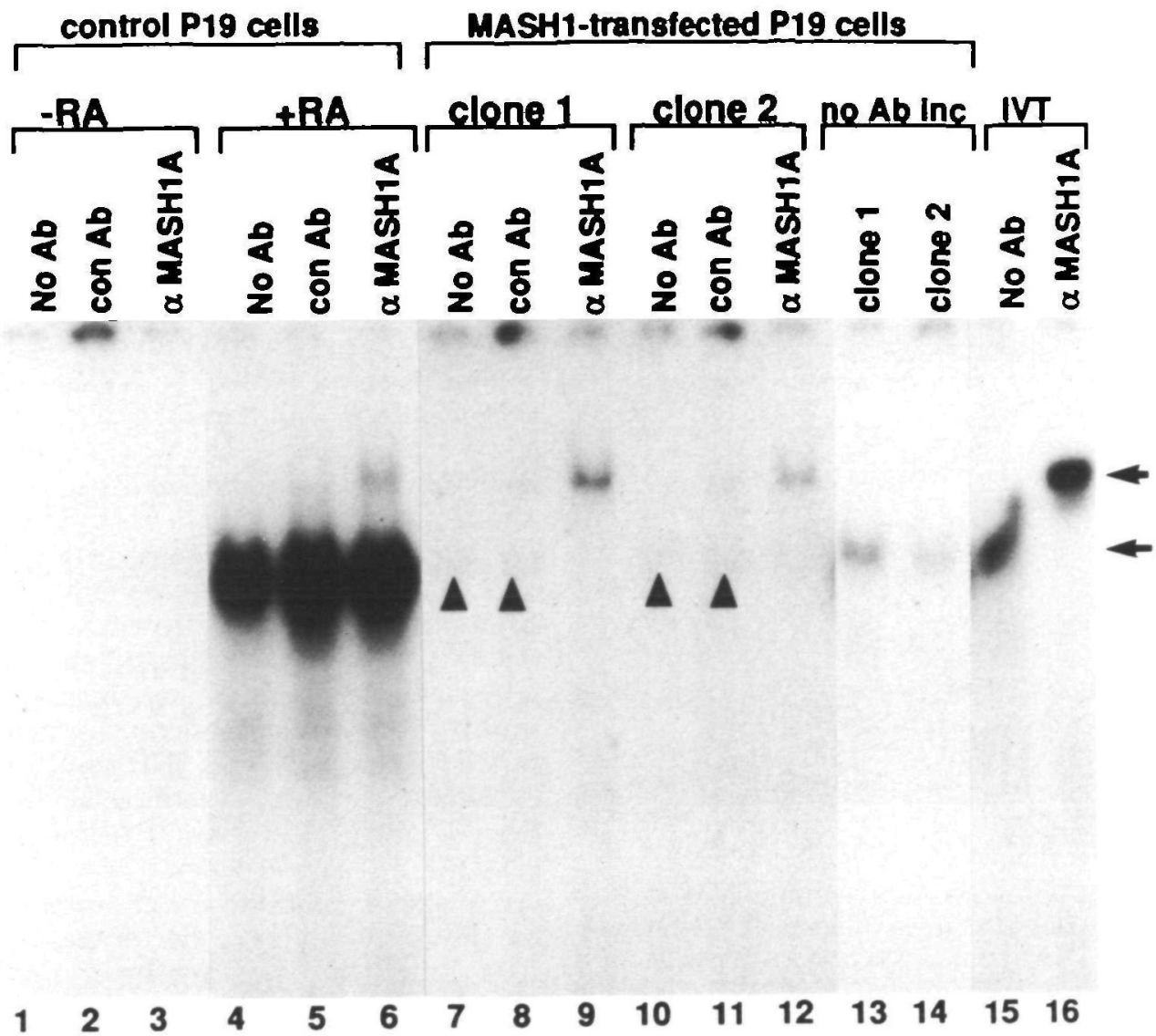

Fig. 9. Stably transfected MASH1 is able to bind an MCK E-box-containing oligonucleotide in nuclear extracts of undifferentiated P19 cells. An antibody supershift experiment was performed as in Fig. 7. Two independent MASH1expressing clones ("clone 1" and "clone 2") contain an E-box-binding activity that is supershifted by the anti-MASH1A monoclonal antibody (lanes 9 and 12; indicated by upper arrow). The supershifted band co-migrates with the band obtained by supershifting in vitro-translated MASH1 + E12 (lane 16), or nuclear extracts from wild-type retinoic-acidtreated P19 cells (lane 6). In extracts incubated without antibody (lanes 7 and 10) or with control antibody (lanes 8 and 11 ), a weaker, faster-migrating band is seen (indicated by triangles); this band co-migrates with in vitro-translated MASH1 + E12 incubated in the absence of antibody (lane 15; indicated by lower arrow). If the shift assay is performed without any antibody incubation (see Materials and Methods), the amount of the MASH1-shifted band in the two clones is increased (lanes 13 and 14; compare with lanes 7 and 10), perhaps indicating that proteolytic degradation occurs during the antibody incubation. The intensity of the shifted band reflects the relative proportion of MASH1 expression in the two clones, as determined by immunocytochemistry (data not shown). Note that no shifted species are obtained with extracts from non-transfected P19 cells grown without retinoic acid (lanes 1-3; see also Fig. 7).

entiation, the P19 embryonal carcinoma cells. Our previous studies (Johnson et al., 1990) indicated that MASH1 is constitutively expressed in two cell lines derived from the peripheral sympathoadrenal lineage (Patterson, 1990): PC12 cells (Greene and Tischler, 1976) and MAH cells (Birren and Anderson, 1990). Although these cell lines can be triggered to extend neurites in response to specific growth factors such as FGF and NGF, only a modest up-regulation of MASH1 expression is detected under these conditions. By contrast, MASH1 mRNA and protein are undetectable in undifferentiated P19 cells but are induced upon retinoic acid treatment. This difference may reflect the likelihood that $\mathrm{MAH}$ and $\mathrm{PC} 12$ cells are already determined for a neurogenic fate, whereas in the developmentally earlier P19 line such a determination event has not yet occurred. Thus, P19 cells constitute the only model system so far identified in which the regulation and function of MASH1 can be studied during early events in neurogenesis.

\section{The features of MASH1 regulation in P19 cells are} similar to those observed in vivo

Our recent studies of MASH1 expression in vivo (Lo et al., 1991) have revealed four basic features of regulation of this gene which appear to be preserved by P19 cells. First, MASH1 expression is restricted to the embryonic nervous system; expression in non-neuronal tissues so far has not been detected. In P19 cells, MASH1 is induced in parallel with neuronal differentiation by retinoic acid, and immunoreactivity is observed in the nuclei of cells expressing neuronal cell surface markers. These data suggest that in P19 cells, as in vivo, the induction of MASH1 is specifically associated with neurogenesis. Second, as in vivo, 
MASH1 induction in P19 cells precedes the earliestdetectable expression of neuronal terminal differentiation markers: we observed MASH1 immunoreactivity prior to HNK-1 or 5A5 expression. Third, in vivo, MASH1 expression is extinguished concomitant with overt neuronal differentiation; similarly, process-bearing 5A5-positive neurons in P19 cultures were invariably MASH1-negative. Fourth, MASH1 expression in the embryonic nervous system is restricted to spatially segregated domains of neuroepithelium. Our observations suggest that MASH1 expression may be similarly restricted to a subset of neurogenic P19 cells (but see below). Taken together, these data suggest that in P19 cells, the expression of MASH1 displays many of the same characteristics as observed in vivo. This system may therefore permit a detailed analysis of the factors and mechanisms that regulate MASH1 expression during neurogenesis.

Fate of MASH1-expressing P19 cells

MASH1 protein appears in the nuclei of retinoic-acidtreated P19 cells one day prior to the appearance of 5A5 immunoreactivity. Subsequently, many MASH1expressing cells co-express 5A5. At later times, 5A5positive neurons are invariably MASH1-negative. These data suggest the progression $\mathrm{MASH}^{-}$, $5 \mathrm{A5}^{-} \rightarrow \mathrm{MASH}^{+}, \quad 5 \mathrm{~A}^{-} \rightarrow \mathrm{MASH}^{+}, \quad 55^{+} \rightarrow$ $\mathrm{MASH}^{-}, 5 \mathrm{~A} 5^{+}$during the neuronal differentiation of P19 cells. Unfortunately, the fact that MASH1 is a nuclear protein presently precludes the isolation of living MASH $1^{+}$cells to directly determine their fate(s). The number of $\mathrm{MASH}^{+}$cells appears small relative to

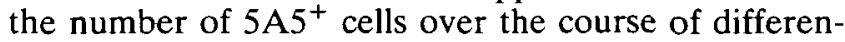
tiation. This difference could reflect different sensitivities or selectivities of the methods used to measure MASH1 and 5A5 expression. However the antibody supershift data (Fig. 7) indicate that MASH1 represents a small fraction of the total E-box-binding activity induced by retinoic acid. Taken together these data are consistent with the idea that MASH1 is expressed by a subset of differentiating P19 cells. This could reflect a situation in which all $5 \mathrm{~A} 5^{+}$cells derive from MASH $1^{+}$ precursors, but expression of MASH1 is highly transient and asynchronous in the cell population. Alternatively, only some $5 \mathrm{~A}^{+}$neurons may derive from $\mathrm{MASH}^{+}$precursors. There is evidence for phenotypic heterogeneity in the P19 neuronal population (M. McBurney, personal communication), heterogeneity that is not revealed by pan-neuronal markers such as 5A5. Moreover, MASH1 is expressed by subsets of neural precursors in vivo. We therefore currently favor the idea that MASH1 is transiently expressed, by a subset of neuronal precursors in P19 cells. Further studies with more specific markers will be necessary to clarify this issue, however.

\section{Role of retinoic acid in the induction of MASH1}

MASH1 is induced in P19 cells by a two day exposure to retinoic acid, but peak mRNA levels are not attained until day 6 . The slow kinetics of MASH1 mRNA accumulation may reflect a long half-life of the message, asynchrony in the cell population, or the involvement of secondary events in an induction cascade rather than a direct action of the retinoic acid receptor on the MASH1 promoter. A number of growth factors or putative growth factors, such as TGF $\beta$ (Mummery et al., 1990), int-1 (Schuuring et al., 1989; St.-Arnaud et al., 1989) and interferon (D. Skup, personal communication) are induced to maximal levels within 48 hours of exposure of P19 cells to retinoic acid. It is possible that the primary effect of retinoic acid may be to induce the expression of such extracellular factors which by signalling through appropriate receptors may then induce MASH1. Such a mechanism would be consistent with the requirement for aggregation, in addition to retinoic acid treatment, to achieve efficient induction of both MASH1 expression and neuronal differentiation. The availability of blocking antibodies to various growth factors induced by retinoic acid in P19 cells may permit an assessment of their involvement in MASH1 induction.

The induction of MASH1 by retinoic acid is also of interest in light of the observation that the earliest expression of MASH1 in vivo is detected in cells lying immediately adjacent to the floorplate in the ventral spinal cord (Lo et al., 1991). Transplantation and extirpation experiments have revealed that the floorplate exerts an inductive influence on the pattern of cellular differentiation in the ventral spinal cord (Yamada et al., 1991). One candidate for a floorplatederived inducing signal is retinoic acid (Wagner et al., 1990). The induction of MASH1 by retinoic acid in P19 cells is consistent with the idea that MASH1 expression in the ventral spinal cord is controlled by floorplatederived retinoic acid. This hypothesis should be testable by examining MASH1 immunoreactivity following in vivo transplantation experiments or in vitro tissue recombination experiments.

\section{Reciprocal regulation of $M A S H 1$ and $M A S H 2$}

An unexpected result of these studies was that the expression of MASH1 and MASH2 mRNAs is reciprocally regulated during neuronal differentiation of P19 cells. In Drosophila, the four homologous transcription units of the achaete-scute complex are all involved in neuronal determination. Given the $>90 \%$ sequence identity between the two MASH genes in the bHLH region, and the neuronal-specific expression of MASH1 in vivo, we expected to find the expression of both MASH1 and MASH2 correlated with neuronal differentiation in P19 cells. Indeed, we previously observed that both MASH genes are expressed, albeit at vastly different levels, in MAH cells and PC12 cells, but not in non-neuronal cells (Johnson et al., 1990; K. Zimmerman, unpublished data). The present data are the first indication that MASH1 and MASH2 may be expressed in different cell types, and suggest that these two genes may play different roles during development. In support of this idea, in situ hybridization data indicate that high levels of MASH2 mRNA are expressed in the ectoplacental cone, an extra-embryonic structure (unpublished observations). Furthermore, preliminary 
gene mapping data indicate that, in contrast to their Drosophila counterparts, MASH1 and MASH2 are located on different chromosomes in the mouse $(\mathrm{N}$. Jenkins and U. Francke, personal communications). The failure to conserve a linked arrangement of MASH genes in evolution may be related to the failure to conserve their tissue-specificity and, presumably, their function.

\section{MASH1 is not sufficient to promote neuronal differentiation of $P 19$ cells}

In an initial attempt to examine the function of MASH1 in P19 cells, we have achieved forced expression of this gene in the undifferentiated cells by stable transformation with a MASH1 cDNA under the control of a strong constitutive promoter. In the case of MyoD, a muscle-specific relative of MASH1, forced expression is sufficient to activate the endogenous myogenic program in a number of different cell types (Davis et al., 1987; Weintraub et al., 1989). Forced expression of MASH1, however, appears insufficient to induce neurogenesis. Nevertheless P19 cells are in principle competent to undergo such differentiation, as shown by the effect of retinoic acid.

These-negative results must be interpreted with caution as the exogenous MASH1 protein may not be biologically active. However, gel shift experiments using extracts from the stably transfected cells indicate that the exogenous MASH1 protein is able to bind to DNA (Fig. 9). In addition, in a separate series of experiments we have shown that transfected MASH1 is able to activate transcription from an exogenous muscle creatine kinase enhancer in both $10 \mathrm{~T} 1 / 2$ cells and P19 cells (Johnson et al., submitted). These data imply that at least some of the transfected MASH1 protein is biologically active, supporting the conclusion that MASH1 alone is insufficient to induce neurogenesis in P19 cells. In this respect, MASH1 is not analogous in function to MyoD, despite its structural similarity. We cannot rule out the possibility that MASH1 would be sufficient for neurogenesis in a different cell context. However, transfection of MASH1 expression constructs into a number of different cell lines has failed to reveal any detectable phenotypic changes (K. Z. and J. E. J., unpublished data).

A reasonable explanation for our results is that MASH1 may act in combination with other factors in P19 cells, and therefore be necessary but not sufficient for neuronal determination. Our observations suggest that a critical test of this hypothesis may be difficult. As MASH1 may be expressed in a small subset of differentiating P19 cells, elimination of its function (by antisense or other methods) would be expected to produce a barely detectable decrease in the proportion of cells expressing pan-neuronal markers such as $5 \mathrm{~A} 5$. (We have not identified other neuronal markers that uniquely co-localized with MASH1 in P19 cells.) However the implication that differentiating P19 cells may express other E-box-binding protein(s) besides MASH1 suggests that perturbations that interfere with the activity of bHLH proteins as a family (Benezra, et al., 1990) may prove successful in this system. Studies such as these should provide a useful complement to experiments aimed at interfering with MASH1 function during embryogenesis in vivo.

We thank Dr. Thomas Jessell for suggesting the use of P19 cells and for providing the line, Dr. Jane Dodd for providing monoclonal antibody 5A5, Dr. Michael McBurney for helpful discussions and Dr. Scott Fraser for his time and the use of his microscope and software. We acknowledge Mr. John Montgomery for constructing the RSV expression vector, Ms. Liching Lo for cloning and analyzing MASH1-transfected P19 cells, Mr. Steven Padilla for excellent technical assistance, Ms. Rochelle Diamond for performing cell sorting, and Ms. Helen Walsh for help in preparation of the manuscript. We thank Barbara Wold, Kai Zinn, Liching Lo and Chris Schoenherr for their critical reading of the paper. JEJ was supported by an MDA postdoctoral fellowship, and $\mathrm{KZ}$ by an NIH postdoctoral fellowship. TS is an Associate and DJA an Assistant Investigator of the Howard Hughes Medical Institute. This work was supported in part by a Sloan Foundation Fellowship in Neuroscience to DJA, and an NSF Presidential Young Investigator Award.

\section{References}

Abo, T. and Balch, C. M. (1981). A differentiation antigen of human NK and $K$ cells identified by a monoclonal antibody (HNK-1). J. Immunol 127, 1024-1029.

Anderson, C. W., Lewis, J. B., Atkins, J. F. and Gesteland, R. F. (1974). Cell-free synthesis of adenovirus 2 proteins programmed by fractionated messenger RNA: a comparison of polypeptide products and messenger RNA lengths. Proc. Natl. Acad. Sci. USA 71, 2756-2760.

Benezra, R., Davis, R. L., Lockshon, D., Turner, D. L. and Weintraub, H. (1990). The protein Id: a negative regulator of helixloop-helix DNA binding proteins. Cell 61, 49-59.

Birren, S. J. and Anderson, D. J. (1990). A v-myc-immortalized sympathoadrenal progenitor cell line in which neuronal differentiation is initiated by FGF but not NGF. Neuron 4, 189-201.

Cabrera, C. V., Martinez-Arias, A. and Bate, M. (1987). The expression of three members of the achaete-scute gene complex correlates with neuroblast segregation in Drosophila. Cell 50, 425433.

Campuzano, S., Carramolino, L., Cabrera, C. V., Ruiz-Gomez, M., Villares, R., Boronat, A. and Modolell, J. (1985). Molecular genetics of the achaete-scute gene complex of D. melanogaster. Cell 40, 327-338.

Cubas, P., de Celts, J.-F., Campuzano, S. and Modolell, J. (1991). Proneural clusters of achaete-scute expression and the generation of sensory organs in the Drosophila imaginal wing disc. Genes and Dev. 6, 996-1008.

Davts, R. L., Cheng, P. F., Lassar, A. B. and Weintraub, H. (1990). The MyoD DNA binding domain contains a recognition code for muscle-specific gene activation. Cell 60, 773-746.

Davis, R. L., Weintraub, H. and Lassar, A. B. (1987). Expression of a single transfected cDNA converts fibroblasts to myoblasts. Cell $\mathbf{5 1}$, 987-1000.

Dodd, J., Morton, S. B., Karagogeos, D., Yamamoto, M. and Jessell, T. M. (1988). Spatial regulation of axonal glycoprotein expression of subsets of embryonic spinal neurons. Neuron 1, 105-116.

Edwards, M. K. S., Harris, J. F. and McBurney, M. W. (1983). Induced muscle differentiation in an embryonal carcinoma cell line. Mol. Cell. Biol. 3, 2280-2286.

Enoch, T., Zinn, K. and Maniatis, T. (1986). Activation of the human b-interferon gene requires an interferon-inducible factor. $\mathrm{Mol}$. Cell. Biol. 6, 801-810.

Ghysen, A. and Dambly-Chaudiere, C. (1988). From DNA to form: the achaete-scute complex. Genes and Dev. 2, 495-501.

Gonzalez, F., Romani, S., Cubas, P., Modolell, J. and Campuzano, S. 
(1989). Molecular analysis of the asense gene, a member of the achaete-scute complex of Drosophila melanogaster, and its novel role in optic lobe development. EMBO Journal 8, 3553-3562.

Greene, L. A. and Tischler, A. S. (1976). Establishment of a noradrenergic clonal line of rat adrenal pheochromocytoma cells which respond to nerve growth factor. Proc. Natl. Acad. Sci. USA 73, 2424-2428.

Gunning, P., Ponte, P., Okayama, H., Engel, J., Blau, H. and Kedes, L. H. (1983). Isolation and characterization of full-length cDNA clones for human $\alpha-, \beta$, and $\gamma$-actin mRNAs: skeletal but not cytoplasmic actins have an amino-terminal cysteine that is subsequently removed. Mol. Cell. Biol. 3, 787-795.

Jaynes, J. B., Johnson, J. E., Buskin, J. N., Gartside, C. L. and Hauschka, S. D. (1988). The muscle creatine kinase gene is regulated by multiple upstream elements, including a musclespecific enhancer. Mol. Cell. Biol. 8, 62-70.

Johnson, J. E., Birren, S. J. and Anderson, D. J. (1990). Two rat homologues of Drosophila achaete-scute specifically expressed in neuronal precursors. Nature 346, 858-861.

Jones-Vllleneuve, E. M. V., McBurney, M. W., Rogers, K. A. and Kalnins, V. I. (1982). Retinoic acid induces embryonal carcinoma cells to differentiate into neurons and glial cells. J. Cell Biol. 94, 253-262.

Jones-Villeneuve, E. M. V., Rudnicke, M. A., Harris, J. F. and McBurney, M. W. (1983). Retinoic acid-induced neural differentiation of embryonal carcinoma cells. Mol. Cell. Biol. 3, 2271-2279.

Krause, M., Fire, A., Harrison, S., Priess, J. and Weintraub, H. (1990). CeMyoD accumulation defines the body wall muscle cell fate during C. elegans embryogenesis. Cell 63, 907-919.

Lassar, A. B., Buskin, J. N., Lockshon, D., Davis, R. L., Apone, S., Hauschka, S. D. and Weintraub, H. (1989). MyoD is a sequencespecific DNA binding protein requiring a region of myc homology to bind to the muscle creatine kinase enhancer. Cell 58, 823-831.

Lo, L., Johnson, J. E., Wuenschell, C. W., Saito, T. and Anderson, D. J. (1991). Mammalian achaete-scute homolog 1 is transiently expressed by spatially-restricted subsets of early neuroepithelial and neural crest cells. Genes and Dev. 5, 1529-1537.

Luscher, B. and Eisenman, R. N. (1990). New light on Myc and Myb. Part I. Myc. Genes and Dev. 4, 2025-2035.

McBurney, M. W., Reuhl, K. R., Ally, A. I., Nasipuri, S., Bell, J. C. and Craig, J. (1988). Differentiation and maturation of embryonal carcinoma-derived neurons in cell culture. J. Neurosci. 8, 10631073.

Melton, D., Krieg, P., Rebagliatl, M., Maniatis, T., Zinn, K. and Green, M. (1984). Efficient in vitro synthesis of biologically active RNA and RNA hybridization probes from plasmids containing a bacteriophage SP6 promoter. Nuc. Actds Research 12, 7035-7056.

Michelson, A. M., Abmayr, S. M., Bate, M., Arias, A. M. and Maniatis, T. (1990). Expression of a MyoD family member prefigures muscle pattern in Drosophila embryos. Genes and Dev. 4, 2086-2097.

Mummery, C. L., Slager, H., Kruljer, W., Feijen, A., Frennd, E., Koornneef, 1. and van den Eijnden-van Raaij, A. J. M. (1990). Expression of transforming growth factor $\beta_{2}$ during the differentiation of murine embryonal carcinoma and embryonic stem cells. Dev. Biol. 137, 161-170.

Murre, C., McCaw, P. S. and Baltimore, D. (1989a). A new DNA binding and dimerization motif in immunoglobin enhancer binding, daughterless, $M y o D$ and $m y c$ proteins. Cell 56, 777-783.

Murre, C., McCaw, P. S., Vaessin, H., Caudy, M., Jan, L. Y., Jan,
Y. N., Cabrera, C. V., Buskin, J. N., Hauschka, S. D., Lassar, A. B., Weintraub, H. and Baltimore, D. (1989b). Interactions between heterologous helix-loop-helix proteins generate complexes that bind specifically to a common DNA sequence. Cell 58, 537-544.

Murre, C., Voronova, A. and Baltimore, D. (1991). B-cell and myocyte-specific E2-box-binding factors contain E12/E47-like subunits. Mol. Cell. Bio. 11, 1156-1160.

Patterson, P. H. (1990). Control of cell fate in a vertebrate neurogenic lineage. Cell 62, 1035-1038.

Romani, S., Campuzano, S., Macagno, E. R. and Modolell, J. (1989). Expression of achaete and scute genes in Drosophila imaginal dises and their function in sensory organ development. Genes and Dev. 3, $997-1007$.

Rudnickl, M. A., Ruben, M. and McBurney, M. W. (1988). Regulated expression of a transfected human cardiac actin gene during differentiation of multipotential murine embryonal carcinoma cells. Mol. Cell. Biol. 8, 406-417.

Schreiber, E., Matthias, P., Muller, M. M. and Schaffner, W. (1989) Rapid detection of octamer binding proteins with 'mini-extracts', prepared from a small number of cells. Nucleic Acids Res. 17, 6419.

Schuuring, E., van Deemter, L., Roelink, H. and Nusse, R. (1989). Transient expression of the proto-oncogene int-1 during differentiation of P19 embryonal carcinoma cells. Mol. Cell. Biol. 9, 1357-1361.

Solter, D. and Knowles, B. B. (1978). Monoclonal antibody defining a stage-specific mouse embryonic antigen (SSEA-1). Proc. Natl. Acad. Sci. USA 75, 5565-5569.

St.-Arnaud, R., Craig, J., McBurney, M.W. and Papkoff, J. (1989). The int-1 protooncogene is transcriptionally activated during neuroectodermal differentiation of P19 mouse embryonal carcinoma cells. Oncogene 4, 1077-1080.

Villares, R. and Cabrera, C. V. (1987). The achaete-scute gene complex of D. melanogaster: conserved domains in a subset of genes required for neurogenesis and their homology to myc. Cell 50, 415-424

Wagner, M., Thaller, C., Jessell, T. M. and Eichele, G. (1990). Polarizing activity and retinold synthesis in the floor plate of the neural tube. Nature 345, 819-822.

Weintraub, H., Davis, R., Tapscott, S., Thayer, M., Krause, M., Benezra, R., Blackwell, T. K., Turner, D., Rupp, R., Hollenberg, S., Zhuang, Y. and Lassar, A. (1991). The myoD gene family: nodal point during specification of the muscle cell lineage. Science 251, 761-766.

Weintraub, H., Tapscott, S. J., Davis, R. L., Thayer, M. J., Adam, M. A., Lassar, A. B. and Miller, A. D. (1989). Activation of musclespecific genes in pigment, nerve, fat, liver, and fibroblast cell lines by forced expression of MyoD. Proc. Natl. Acad. Sci. USA 86, 5434-5438.

Wigler, M., Pellicer, A., Silverstein, S., Axel, R., Urlaub, G. and Chasin, L. (1979). DNA-mediated transfer of adenine phosphoribosyltransferase locus into mammalian cells. Proc. Natl. Acad. Sci. USA 76, 1373-1376.

Yamada, T., Placzek, M., Tanaka, H., Dodd, J. and Jessell, T. M. (1991). Control of cell pattern in the developing nervous system: polarizing activity of the floor plate and notochord. Cell 64, 635647.

(Accepted 19 September 1991) 